\title{
Validation and Invariance of the Dental Anxiety Scale in a Brazilian sample
}

\section{Fernanda Salloume Sampaio BONAFÉ(a) \\ Juliana Alvares Duarte Bonini CAMPOS(b)}

(a) Universidade Estadual Paulista - UNESP, Araraquara School of Dentistry, Araraquara, São Paulo, SP, Brazil.

(b) Universidade Estadual Paulista - UNESP, Araraquara School of Dentistry and Pharmaceutical Sciences, São Paulo, SP, Brazil.

Declaration of Interests: The authors certify that they have no commercial or associative interest that represents a conflict of interest in connection with the manuscript.

\section{Corresponding Author:}

Juliana Alvares Duarte Bonini Campos

E-mail: jucampos@fcfar.unesp.br

DOI: 10.1590/1807-3107BOR-2016.vol30.0138

Submitted: Feb 14,2016

Accepted for publication: Oct 21,2016

Last revision: Nov 1, 2016
Abstract: The aim of this study was to evaluate the properties of the Dental Anxiety Scale (DAS) when applied to Brazilian adults and to test its invariance across independent samples and different sociodemographic groups. Sociodemographic data, reports on previous unpleasant dental experiences and DAS responses were collected through telephone interviews. Metric properties of the one and two-factor models were evaluated using confirmatory factor analysis. The analysis included the chi-square ratio divided by degrees of freedom $\left(\chi^{2} / \mathrm{df}\right)$, the comparative fit index (CFI), the goodness of fit index (GFI) and the root mean square error of approximation (RMSEA). Convergent validity was evaluated using the average variance extracted (AVE). Cronbach's alpha $(\alpha)$ and composite reliability (CR) were calculated. In the two-factor model, discriminant validity was evaluated. The invariance of the models was evaluated using a multigroup analysis of the independent samples $\left(\mathrm{p} \Delta \chi^{2} \lambda, \mathrm{p} \Delta \chi_{{ }_{\mathrm{i}}}^{2}\right.$ and $\left.\mathrm{p} \Delta \chi^{2}{ }_{\text {Res }} \geq 0.05\right)$. Telephone interviews were held with 350 individuals (74.3\% women). Of the participants, 135 (38.6\%) had previous unpleasant dental experiences, and 117 (33.4\%) knew someone who had had this type of experience. The oneand two-factor model $\left(\chi^{2} / \mathrm{df}<2.0 ;\right.$ CFI,GFI $>0.90$; RMSEA $<0.10$; AVE $>0.50 ; \alpha, C R>0.70)$ were adjusted to the data. Discriminant validity was limited $\left(\rho^{2}=0.66\right)$. Both models presented strong invariance across independent samples, but the invariance was weak $\left(\mathrm{p} \Delta \chi^{2} \mathrm{i}<0.05\right)$ when samples were defined by socioeconomic variables. In conclusion, both DAS models were valid and reliable when applied to a sample of Brazilian adults. However, the weak invariance of the models suggests that sample characteristics interfered with the measurement of dental anxiety.

Keywords: Dental Anxiety; Weights and Measures; Reproducibility of Results, Psychometrics.

\section{Introduction}

Anxiety over dental treatment is an important factor that can impact individuals' oral health. Armfield and Ketting ${ }^{1}$ affirm that decisions on whether or not to seek dental treatment are associated with the anxiety felt toward the treatment. Farhad Mollashahi ${ }^{2}$ and Almoznino et al. ${ }^{3}$ report that, in addition to the negative impact on decisions, on access, and on the person's consent to receive routine dental treatment, anxiety 
can also worsen overall quality of life. Furthermore, a series of factors, including negative thoughts, loss of sleep, changes in eating habits, and increased use of medication may accompany this anxiety.

The prevalence of dental anxiety in adults has been estimated in different populations, and found to vary from 5 to $40 \%{ }^{3,4,5,6}$ Many researchers ${ }^{1,3,5,7,8,9,10,11}$ have sought to better understand the psycho-social characteristics that may be linked to this anxiety and its impact on people's lives. However, for this type of protocol to be properly implemented, the use of valid and reliable measurement instruments is necessary.

Dental anxiety is frequently evaluated using psychometric instruments, in which the variable is measured indirectly. Thus, the central measurement (in this case, dental anxiety) is classified as a latent variable. Unlike directly measured variables (observed variables), latent variables require specific research protocols that include an investigation into the psychometric qualities of the measurement instrument. This investigation is a fundamental step for estimating the validity and reliability of the obtained results and should be performed for each sample. Validity and reliability are not properties of the instrument itself, but of the sample. ${ }^{12}$ Esa et al. ${ }^{13}$ reported that studies frequently handle dental anxiety incorrectly, treating it as an observed variable, which leads to measurement errors that could compromise the validity and reliability of conclusions.

The Dental Anxiety Scale (DAS), developed by Corah ${ }^{14}$ in 1969 is a widely used psychometric instrument. This scale was modified by Humphris et al. ${ }^{15}$ in 1995 to produce the Modified Dental Anxiety Scale, or the MDAS. These instruments are available in more than twenty languages (http://www.st-andrews. ac.uk/dentalanxiety/scaletranslations/), including Portuguese. ${ }^{16}$ The psychometric properties of the scale have been determined for English ${ }^{17}$ and Chinese populations ${ }^{18}$ using confirmatory factor analysis; however, only reliability has been evaluated in Brazilian populations. ${ }^{16}$

The decision on whether to use the DAS or the MDAS should be based on the objective of the study. Both scales evaluate dental anxiety one day before a dental appointment, in the waiting room, during the dentist's use of dental tools to perform scaling procedures, and during the use of drills. The MDAS includes a question on local anesthesia, since needle fear, phobia, and anxiety is very common in the general population. ${ }^{19-21}$ However, anxiety over anesthesia may be related to the use of needles in general and not directly associated with dental treatment anxiety; needle anxiety and/or phobia has been well described in the literature. ${ }^{22,23,24,25}$ Thus, the inclusion of this item may interfere in the true assessment of dental anxiety, since procedures involving needles are not exclusive to dentistry and, while interesting, it may overestimate anxiety over dental treatment itself. Another aspect to consider is that not all dental procedures involve anesthesia, particularly in preventative care. Even so, individuals may experience some level of anxiety that may prevent them from seeking dental treatment, and it is very important that these individuals be identified. For this reason, we believe that the four items of the original scale (DAS) are better suited to identify dental care anxiety.

This study was developed in order to evaluate the psychometric properties of the Dental Anxiety Scale when applied to a sample of Brazilian adults, and also to test its invariance across independent samples and across specific subgroups organized by gender, socioeconomic level, and previous unpleasant dental experiences.

\section{Methodology}

\section{Sampling and study design}

A cross-sectional, non-probabilistic sampling study design was used. The minimum sample size was calculated using a sampling process for a finite population. For this calculation, an $n=140,884$ was established (residents of the city of Araraquara in 2008 who were 18 years of age or older according to the Brazilian Institute of Geography and Statistics, or IBGE). A $40 \%$ prevalence of anxiety over dental treatment was also used for this sample population (unpublished data: $n=1,065$ residents of the city of Araraquara - study funded by São Paulo Research Foundation (FAPESP), grant \#2007/04501-3). A 95\% confidence interval was adopted, and a relative error margin was estimated to be $15 \%$. Thus, the minimum sample size was 256 individuals. After considering 
a possible $40 \%$ participant loss, the sample was corrected to 359 households.

\section{Sociodemographic data}

Gender, age, socioeconomic class and level of education data were collected. Socioeconomic classification was done according to the Brazilian Economic Classification Criteria (ABEP), ${ }^{26}$ in which the estimated monthly household income is US\$ 931.00 and higher for Classes A/B, from US $\$ 373.00$ to US $\$ 556.00$ for Class $C$, and below US\$247.00 for Class D/E. The exchange rate at the time was US\$1.00 for R $\$ 2.50$.

\section{Unpleasant dental experience data}

Individuals answered yes/no questions about having a previous unpleasant dental experience and/or knowing someone who had a previous unpleasant dental experience.

\section{Dental anxiety scale}

Dental anxiety was measured with the Portuguese version ${ }^{16}$ of the Dental Anxiety Scale (DAS) ${ }^{14}$. The DAS is composed of 4 items, which explore the level of anxiety that the respondent would feel a day before a dental appointment, in the waiting room, during the use of drills and during the use of dental tools to perform scraping procedures. The answers vary on a scale of 1 (not anxious) to 5 (extremely anxious). In the original scale ${ }^{14}$ the four scores are added, with higher scores indicating higher levels of anxiety. Although the original DAS is based on a one-factor model, a two-factor model (F1: anticipatory dental anxiety and F2: treatment dental anxiety) was presented by Yuan et al. ${ }^{18}$ in a sample of Chinese adults and, in the current study, the two models were evaluated.

\section{Procedures}

Data was collected via telephone interview (sociodemographic data, unpleasant dental experience data, and DAS responses). One of the residents who was 18 years of age or older from each household, was included in the study.

The participating households were chosen at random using maps of the city's census records.
Randomly, a block, then a street from that block and finally four households from that street were chosen: the first household was the first-choice participant. If the phone was not answered or if no one accepted to participate, a second household was randomly chosen from the remaining three. This process continued until a successful call was made. If all four attempts failed to reach a respondent, the group was considered a sample loss. This occurred only nine times in the study. All interviews were performed by the same researcher. Phone calls were made during business hours, at night, and on weekends. If the phone was not answered or the person declined to participate, new phone calls were made to reach another household member. The first-choice participant was the first eligible household member to answer or come to the phone who agreed to participate.

This study was approved by the Ethics Committee on Human Research of the Araraquara School of Dentistry (Protocol No. 17/07). Consent to participate in the study was given by participants after the researcher read aloud the Informed Consent Form.

\section{Statistical analyses}

The psychometric sensitivity of the DAS items were evaluated using the summary and shape measures. Sensitivity was adequate when skewness (Sk) and kurtosis $(\mathrm{Ku})$ presented absolute values below 3 . The factorial validity of the DAS was evaluated using the confirmatory factor analysis (CFA) and the maximum likelihood estimate method. The fit of the model was evaluated using chi-square ratio divided by the degrees of freedom $\left(\chi^{2} / \mathrm{df}\right)$, and also using the comparative fit index (CFI), the goodness of fit index (GFI), and the root mean square error of approximation (RMSEA). Values were considered adequate when $\chi^{2} / \mathrm{df}<2.0, \mathrm{CFI}$ and GFI $>0.90$, and RMSEA $<0.10 .{ }^{23}$ Factor weights $(\lambda)$ below 0.50 were considered inadequate. Convergent validity was evaluated using the average variance extracted (AVE), which was considered adequate when $\geq 0.5 .^{27,28}$

The modification indices, which were calculated using the Lagrange multiplier method (LM), were used to help determine the fit of the model. ${ }^{27}$ The reliability of the scale was evaluated using 
Chronbach's alpha $(\alpha>0.70)$ and composite reliability $(\mathrm{CR}>0.70){ }^{28,29}$

In the two-factor model, discriminant validity was also evaluated using correctional analysis, and it was established if the coefficient of determination between the factors $\left(\rho^{2}\right)$ was less than the AVE of each of the factors. ${ }^{28}$

The Akaike information criterion (AIC), the Bayes information criterion (BIC), and the Browne-Cudeck criterion (BCC) were calculated for each model to determine the most parsimonious model. The lower the values of these indices, the more parsimonious is the model.

The Total sample was randomly divided into a Test Sample (60\% of the sample) and a Validation Sample ( $40 \%$ of the sample) using the SPSS Statistics software. The invariance of each of the models (one- and two-factor) was tested in independent samples as part of a multigroup analysis using the chi-square difference statistic $\left(\Delta \chi^{2}\right)$. The factorial weights, intercepts and the variances/covariances were equalized between the groups. When the hypothesis regarding the invariance of factor weights was acceptable (metric invariance; weak measurement invariance; $\left.\Delta \chi^{2} \lambda: p \geq 0.05\right)$, then the invariance of the intercepts was also analyzed (scalar invariance; strong measurement invariance; $\Delta \chi^{2} \mathrm{i}: \mathrm{p} \geq 0.05$ ), as was the invariance of residual variances (strict invariance; $\Delta \chi^{2}$ Res: $\left.p \geq 0.05\right) .27,30$

Next, the above analyses were performed on specific participant subgroups, based on gender, age, socioeconomic level, and previous unpleasant dental experiences, which are supported by the literature as having a significant impact on dental anxiety. The literature reports that women, ${ }^{16,17,19}$ younger patients, ${ }^{17}$ patients at lower socioeconomic levels, ${ }^{5,19}$ and with previous unpleasant dental experiences ${ }^{18}$ present greater anxiety over dental treatment. These findings may reflect a pattern of response that is distinct to the items of the DAS. For this reason, scalar invariance was tested between these subgroups. Because age is a quantitative variable, the average age of each group was used.

The analyses were performed using the AMOS software, version $21.0^{\circledR}$.

\section{Results}

A total of 350 people with an average age of 45.05 years $(\mathrm{SD}=19.23$; range $=18-89$ years) participated in the study. Their characteristics are detailed in Table1.

The summary and shape measures of the answers to the DAS items are detailed in Table 2.

None of the items severely violated normality.

Figure 1 presents the original one-factor model (A) and the adjusted one-factor model (B) of the DAS.

The quality of fit indices of the original one-factor model (Model A) were not adequate for the validation sample $\left(\chi^{2} / \mathrm{df}=14.500 ; \mathrm{CFI}=0.950 ; \mathrm{GFI}=0.959\right.$; RMSEA $=0.197)$. After the correlation between the errors of items 1 and 2 was inserted $(\mathrm{LM}=21.29)$, the adjusted one-factor model (Model B) presented adequate factorial validity $\left(\chi^{2} / \mathrm{df}=1.506\right.$; $\mathrm{CFI}=0.999$; $\mathrm{GFI}=0.998$; $\mathrm{RMSEA}=0.038$; $\mathrm{AIC}=19.506$; $\mathrm{BIC}=54.227$; and $\mathrm{BCC}=19.767)$. The convergent validity $(\mathrm{AVE}=0.54)$ and reliability $(\alpha=0.83 ; C R=0.82)$ of this model were adequate.

The two-factor model (Model C) can be found in Figure 2 . This model presented adequate factorial fit $\left(\chi^{2} / \mathrm{df}=1.506 ; \mathrm{CFI}=0.999 ; \mathrm{GFI}=0.998 ; \mathrm{RMSEA}=0.038 ;\right.$

Table 1. Characteristics of the population sample.

\begin{tabular}{lc}
\hline Variable & $\mathrm{n}(\%)$ \\
\hline Gender & $90(25.7)$ \\
Male & $260(74.3)$ \\
Female & \\
Socioeconomic class & $195(55.7)$ \\
A/B & $120(34.3)$ \\
C & $35(10.0)$ \\
D/E & \\
Level of education & $18(5.1)$ \\
Literacy & $70(20.0)$ \\
Elementary school & $50(14.3)$ \\
Middle school & $162(46.3)$ \\
High school & $50(14.3)$ \\
Higher education & $135(38.6)$ \\
Reported having previous unpleasant dental experience \\
Yes & $215(61.4)$ \\
No & \\
Reported knowing someone who had a previous unpleasant \\
dental experience \\
Yes \\
No
\end{tabular}


Table 2. Summary and shape measures of the Dental Anxiety Scale (DAS) item responses.

\begin{tabular}{|c|c|c|c|c|}
\hline \multirow{2}{*}{ Variable } & \multicolumn{4}{|c|}{ DAS } \\
\hline & Item 1 & Item 2 & Item 3 & Item 4 \\
\hline Mean & 2.47 & 2.23 & 2.59 & 2.66 \\
\hline Median & 2.00 & 1.00 & 3.00 & 3.00 \\
\hline Mode & 2.00 & 1.00 & 1.00 & 1.00 \\
\hline Standard deviation & 1.19 & 1.40 & 1.40 & 1.33 \\
\hline Minimum & 1.00 & 1.00 & 1.00 & 1.00 \\
\hline Maximum & 5.00 & 5.00 & 5.00 & 5.00 \\
\hline Skewness & 1.05 & 0.56 & 0.31 & 0.31 \\
\hline Kurtosis & 0.22 & -1.27 & -1.16 & -1.02 \\
\hline
\end{tabular}
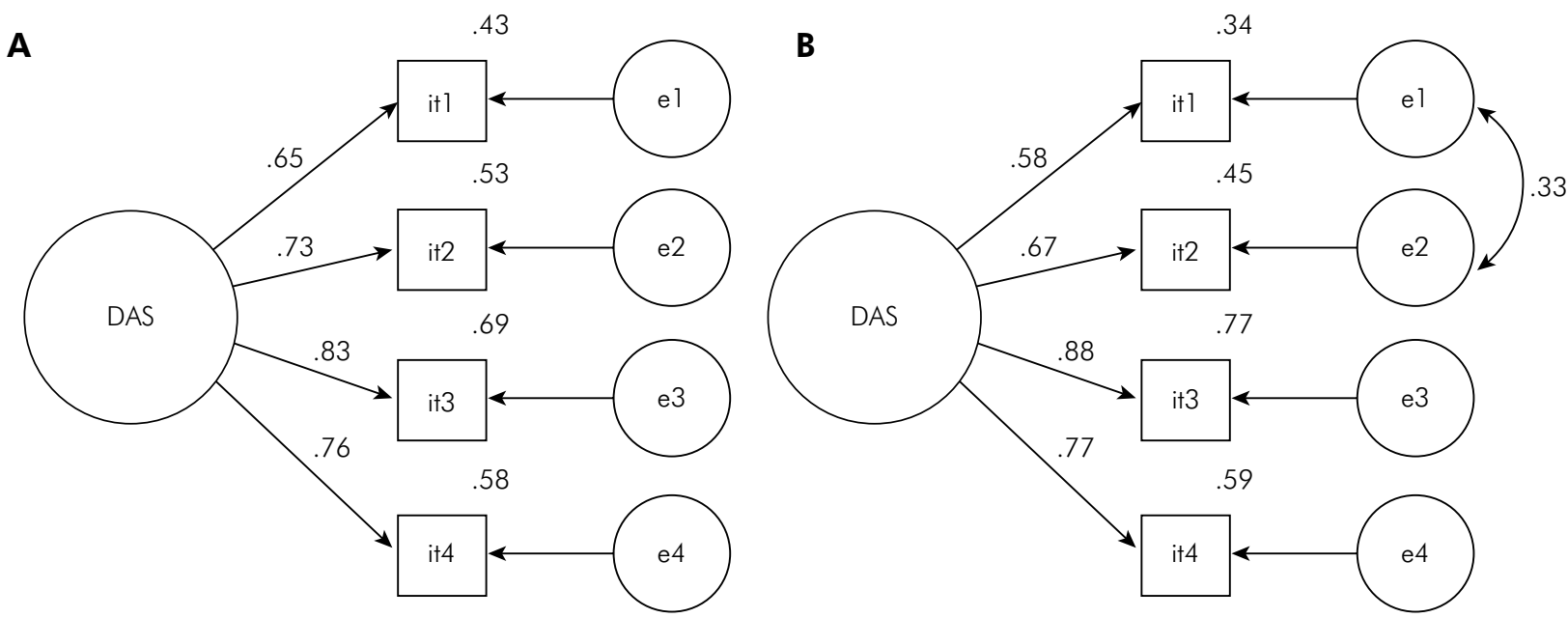

Figure 1. One-factor model ( $A=$ original; $B=$ adjusted) of the Dental Anxiety Scale (DAS).

$\mathrm{AIC}=19.506, \mathrm{BIC}=54.227$, and $\mathrm{BCC}=19.767)$. Convergent validity $\left(\mathrm{AVE}_{\mathrm{F} 1}=0.59 ; \mathrm{AVE}_{\mathrm{F} 2}=0.68\right)$ and reliability of the model $\left(\alpha_{\mathrm{F} 1}=0.73 ; \alpha_{\mathrm{F} 2}=0.80 ; \mathrm{CR}_{\mathrm{F} 1}=0.74\right.$; $\left.\mathrm{CR}_{\mathrm{F} 2}=0.81\right)$ were adequate. Discriminant validity was limited $\left(\rho^{2}=0.66\right)$.

Multigroup analysis (Table 3 ) demonstrated that the one-factor adjusted model and the two-factor model of the DAS presented strict invariance across independent samples and metric/weak invariance between gender, age, and previous unpleasant dental experience groups.

\section{Discussion}

The original version of the DAS has been frequently used, although a thorough psychometric evaluation of the instrument has never been performed. To our

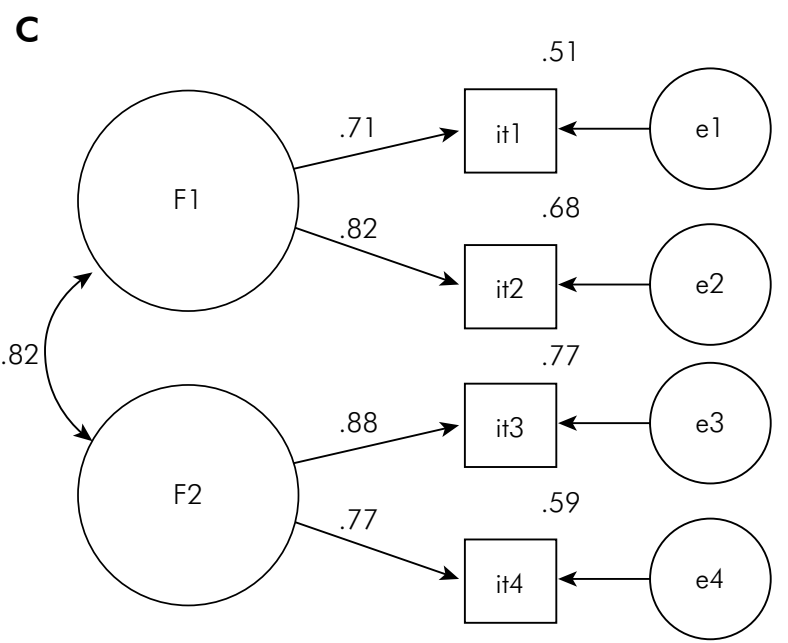

Figure 2. Two-factor model (Model C) of the Dental Anxiety Scale (DAS) (F1: anticipatory dental anxiety; F2: treatment dental anxiety). 
Table 3. Multigroup analysis to determine the invariance of the models across different subsamples.

\begin{tabular}{|c|c|c|c|c|c|c|}
\hline \multirow{2}{*}{ Model } & \multicolumn{3}{|c|}{ Simultaneous CFA } & \multicolumn{3}{|c|}{$\Delta \chi^{2}(p)$} \\
\hline & $\chi^{2} / \mathrm{df}$ & $\mathrm{CFI}$ & RMSEA & $\lambda$ & i & Res \\
\hline \multicolumn{7}{|l|}{ Model B } \\
\hline Test vs Validation & 2.07 & 1.00 & 0.05 & $2.94(0.40)$ & $3.37(0.50)$ & $8.83(0.18)$ \\
\hline Male vs Female & 2.63 & 0.99 & 0.07 & $5.51(0.14)$ & $10.06(0.04)$ & - \\
\hline$<45$ years old $v s \geq 45$ years old & 2.26 & 0.99 & 0.06 & $5.55(0.14)$ & $10.947(0.03)$ & - \\
\hline \multicolumn{7}{|l|}{ Socioeconomic Class } \\
\hline $\mathrm{A} / \mathrm{B}$ vs $\mathrm{C}$ & 0.83 & 1.00 & 0.00 & $7.38(0.06)$ & $15.41(0.01)$ & - \\
\hline C vs D/E & 0.84 & 1.00 & 0.00 & $1.44(0.69)$ & $1.61(0.81)$ & $6.33(0.39)$ \\
\hline $\mathrm{A} / \mathrm{B}$ vs $\mathrm{D} / \mathrm{E}$ & 0.31 & 1.00 & 0.00 & $2.14(0.54)$ & $2.87(0.58)$ & $5.83(0.44)$ \\
\hline $\begin{array}{l}\text { Presence vs lack of personal previous } \\
\text { unpleasant experience }\end{array}$ & 1.67 & 1.00 & 0.04 & $2.36(0.50)$ & $13.94(0.01)$ & - \\
\hline $\begin{array}{l}\text { Presence vs lack of another person's previous } \\
\text { unpleasant experience }\end{array}$ & 1.15 & 1.00 & 0.02 & $4.89(0.18)$ & $9.87(0.04)$ & - \\
\hline \multicolumn{7}{|l|}{ Model C } \\
\hline Test vs Validation & 2.07 & 1.00 & 0.05 & $2.34(0.31)$ & $3.36(0.50)$ & $9.44(0.22)$ \\
\hline Male vs Female & 4.08 & 0.99 & 0.09 & $0.94(0.62)$ & $10.86(0.028)$ & - \\
\hline$<45$ years old $v s \geq 45$ years old & 1.84 & 0.99 & 0.05 & $1.53(0.47)$ & $10.96(0.03)$ & - \\
\hline \multicolumn{7}{|l|}{ Socioeconomic Class } \\
\hline $\mathrm{A} / \mathrm{B}$ vs $\mathrm{C}$ & 0.83 & 1.00 & 0.00 & $4.97(0.08)$ & $14.71(0.01)$ & - \\
\hline C vs D/E & 0.84 & 1.00 & 0.00 & $1.36(0.51)$ & $1.62(0.81)$ & $6.41(0.49)$ \\
\hline$A / B$ vs $D / E$ & 0.31 & 1.00 & 0.00 & $1.39(0.50)$ & $2.63(0.62)$ & $6.82(0.45)$ \\
\hline $\begin{array}{l}\text { Presence vs lack of personal previous } \\
\text { unpleasant experience }\end{array}$ & 1.67 & 1.00 & 0.04 & $2.28(0.32)$ & $13.84(0.01)$ & - \\
\hline $\begin{array}{l}\text { Presence vs lack of another person's previous } \\
\text { unpleasant experience }\end{array}$ & 1.15 & 1.00 & 0.02 & $4.82(0.09)$ & $9.78(0.04)$ & - \\
\hline
\end{tabular}

knowledge, this is the first study to evaluate the psychometric properties of the instrument using confirmatory factor analysis, and its invariance when applied to a Brazilian sample; according to our results, the DAS presented adequate psychometric properties. Campos et al. ${ }^{12}$ reported that the evaluation of the metric properties of a measurement instrument is essential for assuring that the researcher possesses valid and reliable data.

The originally proposed theoretical model of the $\operatorname{DAS}^{14}$ (Figure 1) and the two-factor model proposed by Yuan et al..$^{18}$ (Figure 2) were found to fit adequately to this Brazilian sample, indicating that this scale can be used to investigate dental anxiety. The decision on which model to use should be based on the objective of the investigation: if the focus is anxiety over dental treatment in general, the Model $B$ is recommended. However, if researchers wish to separately evaluate anticipatory anxiety and withintreatment anxiety, the two-factor model (Model C) is recommended. Researchers should bear in mind, however, that this model presented limited discriminate validity.

Another aspect worth highlighting is the invariance of the DAS across independent samples. Both the one- and two-factor models presented strong invariance across independent samples ("Test sample" vs "Validation sample"), a finding which reflects adequate external validity of the results. ${ }^{27}$ Nevertheless, when sociodemographic characteristics were considered, a weak invariance was often found $\left(\mathrm{p} \Delta \chi^{2} \lambda \geq 0.05\right.$ and $\left.\mathrm{p} \Delta \chi^{2} \mathrm{i}<0.05\right)$ (Table 3). Thus, it is clear that the pattern of responses differs depending on the group or groups to which the respondent belongs. These confounding factors may certainly interfere with the final dental anxiety score and, therefore, researchers must consider these variables when planning the study. Among other effects, disregarding these factors may create biased results leading to biased conclusions.

Another important aspect for researchers and healthcare professionals interested in evaluating dental 
anxiety is the need to preserve the latent nature of this construct to increase the quality (precision/accuracy) of the information obtained, and, as a consequence, improve decision-making and minimize criticisms over measurement errors. ${ }^{13}$

It is hoped that this study offers a reflection on the importance of evaluating the metric properties of instruments before applying them on different samples and alert professionals for the need to properly evaluate dental anxiety.

\section{Conclusion}

Both the adjusted one-factor model and the two-factor model of the Dental Anxiety Scale were

\section{References}

1. Armfield JM, Ketting M. Predictors of dental avoidance among Australian adults with different levels of dental anxiety. Health Psychol. 2015;34(9):929-40. doi:10.1037/hea0000186

2. Farhad Mollashahi N. Adult dental patients with avoidance behaviours. Int J High Risk Behav Addict. 2015;4(1):e23547. doi:10.5812/ijhrba.23547

3. Almoznino G, Zini A, Sharav Y, Shahar A, Zlutzky $\mathrm{H}$, Haviv $\mathrm{Y}$ et al. Sleep quality in patients with dental anxiety. J Psychiatr Res. 2015;61(1):214-22. doi:10.1016/j.jpsychires.2014.11.015

4. Gisler V, Bassetti R, Mericske-Stern R, Bayer S, Enkling $\mathrm{N}$. A cross-sectional analysis of the prevalence of dental anxiety and its relation to the oral health-related quality of life in patients with dental treatment needs at a university clinic in Switzerland. Gerodontology.. 2012;29(2):e290-6. doi:10.1111/j.1741-2358.2011.00465.x

5. Goettems ML, Schuch HS, Demarco FF, Ardenghi TM, Torriani DD. Impact of dental anxiety and fear on dental care use in Brazilian women. J Public Health Dent. 2014;74(4):310-6. doi:10.1111/jphd.12060

6. Liu Y, Huang X, Yan Y, Lin H, Zhang J, Xuan D. Dental fear and its possible relationship with periodontal status in Chinese adults: a preliminary study. BMC Oral Health. 2015;15(1):18. doi:10.1186/1472-6831-15-18

7. Carvalho RWF, Falcao PGDB, Campos GJD, Bastos AD, Pereira JC, Pereira MAD et al. [Anxiety regarding dental treatment: prevalence and predictors among Brazilians]. Cienc Saúde Coletiva. 2012;17(7):1915-22. Portuguese. doi:10.1590/S1413-81232012000700031

8. Pakpour AH, Gellert P, Asefzadeh S, Sniehotta FF. Planning predicts dental service attendance and the effect is moderated by dental anxiety and educational found to be valid and reliable when applied to a sample of Brazilian adults. However, the invariance of the models was weak, suggesting that certain characteristics of the sample interfered in the application of the construct (dental anxiety).

\section{Acknowledgments}

The authors would like to thank the grant \#2007/04501-3, São Paulo Research Foundation (FAPESP) for the financial support, and also Cristina Dupim Presoto for her collaboration in data collection.

The authors declare no potential conflicts of interest with respect to the authorship and/or publication of this article.

status: findings from a one-year prospective study. Appl Psychol Health Well-Being g. 2014;6(2):214-29. doi:10.1111/aphw.12025

9. Soares FC, Souto G, Lofrano M, Colares V. Anxiety related to dental care in children and adolescents in a lowincome Brazilian community. Eur Arch Paediatr Dent. 2015;16(2):149-52. doi:10.1007/s40368-014-0146-8

10. Tellez M, Kinner DG, Heimberg RG, Lim S, Ismail AI. Prevalence and correlates of dental anxiety in patients seeking dental care. Community Dent Oral Epidemiol. 2015;43(2):135-42. doi:10.1111/cdoe.12132

11. Houtem CM, Wijk AJ, Jongh A. Presence, content, and characteristics of memories of individuals with dental phobia. Appl Cognit Psychol. 2015;29(4):515-23. doi:10.1002/acp.3127

12. Campos JA, Bonafé FS, Dovigo LN, Maroco J. Avaliação psicométrica da escala de atitudes em relação à estatística. Rev Bras Biometria. 2013;31(2):327-37.

13. Esa R, Ong AL, Humphris G, Freeman R. The relationship of dental caries and dental fear in Malaysian adolescents: a latent variable approach. BMC Oral Health. 2014;14(1):19. doi:10.1186/1472-6831-14-19

14. Corah NL. Development of a dental anxiety scale. J Dent Res. 1969;48(4):596. doi:10.1177/00220345690480041801

15. Humphris GM, Morrison T, Lindsay SJ. The modified dental anxiety scale: validation and United Kingdom norms. Community Dent Health. 1995;12(3):143-50.

16. Hu LW, Gorenstein C, Fuentes D. Portuguese version of Corah's Dental Anxiety Scale: transcultural adaptation and reliability analysis. Depress Anxiety. 2007;24(1):467-71. doi:10.1002/da.20258

17. Humphris GM, Dyer TA, Robinson PG. The modified dental anxiety scale: UK general public population norms in 2008 with further psychometrics and effects of age. BMC Oral Health. 2009;9(1):20. doi:10.1186/1472-6831-9-20 
18. Yuan S, Freeman R, Lahti S, Lloyd-Williams F, Humphris G. Some psychometric properties of the Chinese version of the Modified Dental Anxiety Scale with cross validation. Health Qual Life Outcomes. 2008;6(1):22. doi:10.1186/1477-7525-6-22

19. Armfield JM. The extent and nature of dental fear and phobia in Australia. Aust Dent J. 2010;55(4):368-77. doi:10.1111/j.1834-7819.2010.01256.x

20. Mavridou P, Dimitriou V, Manataki A, Arnaoutoglou E, Papadopoulos G. Patient's anxiety and fear of anesthesia: effect of gender, age, education, and previous experience of anesthesia: a survey of 400 patients. J Anesth. 2013;27(1):104-8. doi:10.1007/s00540-012-1460-0

21. Hakim H, Razak A. Dental fear among medical and dental undergraduates. Sci World J. 2014;2014:Article ID 747508. doi:10.1155/2014/747508

22. Nir Y, Paz A, Sabo E, Potasman I. Fear of injections in young adults: prevalence and associations. Am J Trop Med Hyg. 2003;68(3):341-4.

23. Kose S, Mandiracioglu A. Fear of blood/injection in healthy and unhealthy adults admitted to a teaching hospital. Int J Clin Pract. 2007;61(3):453-7. doi:10.1111/j.1742-1241.2006.01150.x
24. Sokolowski CJ, Giovannitti JA Jr, Boynes SG. Needle phobia: etiology, adverse consequences, and patient management. Dent Clin North Am. 2010;54(4):731-44. doi:10.1016/j.cden.2010.06.012

25. Wright S, Yelland M, Heathcote K, Ng SK, Wright G. Fear of needles: nature and prevalence in general practice. Aust Fam Physician. 2009;38(3):172-6.

26. Associação Brasileira de Empresas de Pesquisa - ABEP. Critério de Classificação Econômica Brasil 2008 [cited 2015 Sep 4]. Available from: http://www.abep.org/ criterio-brasil

27. Marôco J. Análise de equações estruturais: fundamentos teóricos, softwares e aplicações. Lisboa: Report Number; 2014.

28. Fornell C, Larcker DF. Evaluating structural equation models with unobservable variables and measurement error. J Mark Res. 1981;18(1):39-50. doi:10.2307/3151312

29. Maroco J, Garcia-Marques T. Qual a fiabilidade do alfa de Cronbach? Questões antigas e soluções modernas? Lab Psicol. 2006;4(1):65-90. doi:

30. Kaplan D. Structural equation modeling: foundations and extensions. Los Angeles: Sage; 2000. 